HEPATOLOGY

\title{
Intrafamilial prevalence of hepatitis B virus in Western Brazilian Amazon region: Epidemiologic and biomolecular study
}

\author{
Cirley Lobato, ${ }^{*}$ José Tavares-Neto, ${ }^{*}$ Márcio Rios-Leite, ${ }^{*}$ Christian Trepo, ${ }^{\dagger}$ Ludmila Vitvitski, ${ }^{\dagger}$ \\ Parviz Parvaz, ${ }^{\dagger}$ Fabien Zoulim, ${ }^{\dagger}$ Argemiro D’Oliveira $\mathrm{Jr}^{*}$ and Raymundo Paraná* \\ ${ }^{*}$ CPgMS-State of Acre Cooperation Program with University of Bahia, ${ }^{\ddagger}$ Gastro-Hepatology Unit, University Hospital of Bahia, Bahia, Brazil and \\ ${ }^{\dagger}$ INSERM U271, Lyon, France
}

\begin{abstract}
Key words
Acre, Amazon region, HBV, intrafamilial

transmission.

Accepted for publication 14 August 2005.

\section{Correspondence}

Cirley Lobato, Avenue Juracy Magalhães Jr, 2096/510, Salvador, Bahia 41920-000, Brazil. Email: unif@svn.com.br
\end{abstract}

\begin{abstract}
Background: Hepatitis B is endemic in the Amazon region.

Methods: Serological markers for hepatitis B virus (HBV) were determined in 266 household members for hepatitis B surface antigen (HBsAg)-positive women (G1) and 395 household members for HBsAg-negative women (G2), randomly selected in Acre State Women's Medical Care Program, in order to evaluate the prevalence of HBV in this population. Before blood sample collection an epidemiological questionnaire was applied. Results: The overall prevalence of HBV carriers (HBsAg) and exposed individuals (anti-HBc, $\mathrm{IgG}$ ) was, respectively, $21.1 \%$ and $60.5 \%$ in $\mathrm{G} 1$ and $2.8 \%$ and $27.4 \%$ in $\mathrm{G} 2$ $(P<0.0000001)$. The frequency of HBsAg was higher among siblings from group $\mathrm{G} 1$ (75\%) compared to the absence of any HBsAg-positive sibling in G2 $(P<0.00006)$. The HBV markers in other family members was as follows: G1 parents, $27.3 \%$ vs $4.5 \%$ $(P<0.03)$, sexual partners, $21.1 \%$ vs $2.5 \%(P<0.04)$, and offspring, $10.4 \%$ vs $1.5 \%$ $(P<0.04)$. A low prevalence of HBsAg and anti-HBc $(\operatorname{IgG})$ was observed for the last offspring of G2 mothers compared to the high prevalence among children of G1 mothers ( $0 \%$ vs $18.2 \%, P<0.01$ and $2.3 \%$ vs $59.1 \%, P<0.0000005$, respectively), with children younger than 1 year being the most affected. The frequency of the habit of sharing toothbrushes and the presence of at least one HBsAg carrier were higher in G1 than in G2 $(P<0.0001$ and $P<0.000002)$, respectively. Genotypes A, D and $\mathrm{G}$ were found to be predominant by Innolipa test. There were cases that reacted to more than one genotype. Conclusion: Intrafamilial transmission of $\mathrm{HBV}$ is evident in the present study and is possibly associated with the presence of more than one HBV carrier in the family and the shared use of toothbrushes among household contacts. Genotype analysis confirms intrafamilial transmission.
\end{abstract}

(c) 2006 Blackwell Publishing Asia Pty Ltd

\section{Introduction}

The prevalence of hepatitis B virus (HBV) infection is widely heterogeneous in Brazil. The Amazon region presents the highest HBV endemicity. The prevalence of hepatitis B surface antigen (HBsAg) ranges from 3 to $10 \%$ and more than $70 \%$ of individuals have evidence of previous exposure to HBV. ${ }^{1,2}$ However, the epidemiological aspects and transmission of HBV infection in the Amazon region are unclear, especially the conditions favoring this high endemicity. 3,4

It has been suggested that HBV is transmitted through direct or indirect personal contact between household members, possibly through non-apparent per oral, per mucosal or percutaneous passage. ${ }^{5}$ Other transmission routes are well-ocumented in this area such as vertical and sexual, but seroconversion after 1 year of birth strongly suggests the importance of intrafamilial transmission. ${ }^{6}$ In this particular case, factors such as sharing of personal hygiene accessories, family size, presence of more than one HBsAg carrier among household contacts, replicative status of the carrier, and ethnic origin should be taken into account. ${ }^{7}$

The aim of the present study was to determine the prevalence of HBsAg in family members of HBV-infected women, as well as possible risk factors related to the intrafamilial transmission of HBV. 


\section{Methods}

\section{Study population}

A total of 3789 pregnant women enrolled in the public prenatal care program of the municipality of Rio Branco, Acre State, located in Western Brazilian Amazon underwent routine prenatal exams at the Central Laboratory (LACEN, Acre). Eighty-four $(2.2 \%)$ of these women were positive for HBsAg and 22 fulfilled the inclusion criteria (G1), that is, residence in Rio Branco, being found at home after three attempts, and being willing to participate in the study. The control group (HBsAg-negative women, G2) was matched for age ( \pm 5 years) and place of residence at a proportion of 1:2. Household contacts included individuals living in the same dwelling or in the peridomiciliary area. A total of 72 nuclear family household contacts of G1 and 155 of G2 were contacted. Fifteen individuals were excluded, six from G1 and nine from G2, including seven sex partners and eight children, after three negative attempts to find them at home or because they refused to participate in the study. In addition, 194 (G1) and 248 (G2) members of the family of origin, including parents, siblings, nephews, uncles and grandparents, were enrolled in this study. The addresses of the index (G1) and control (G2) cases were obtained from the simplified notification record from the prenatal unit. The individuals were visited at home, and after the objective of the study was explained to them, they signed a free informed consent form. Then a specific epidemiologic questionnaire related to demographic, personal, socioeconomic, behavioral, epidemiological, and family variables was applied.

\section{Laboratory tests}

Blood samples were collected in previously identified vacutainer tubes containing separator gel, placed on ice and transported to the laboratory. Sera were shared in three aliquots and stored at $-20^{\circ} \mathrm{C}$. One aliquot was tested for HBsAg, antibody to hepatitis B core antigen (anti-HBc; IgG), hepatitis B e antigen ( $\mathrm{HBeAg}$ ) and antibody to hepatitis $\mathrm{B}$ e antigen (anti-HBe) markers using commercial kits (Hepanostika-Organon, the Netherlands). Another aliquot was tested for anti-hepatitis D, human immunodeficiency virus, Lues serology and antibody to hepatitis B surface antigen (anti-HBs) markers by ELISA using commercial kits (Hepanostika-Organon;
Sanofi-Pasteur-Plus, Paris, France). A third aliquot was stored for biomolecular studies. Quantification of serum HBV-DNA was performed by commercial Kit Amplicor (Roche-Diagnostic Basel). The HBV genotypes were determined by InnoLiPA (Innogenetics, Belgium) at INSERM U271.

\section{Statistical analysis}

The data were recorded using SPSS software (SPSS, Chicago, IL, USA). Differences between proportions were analyzed using nonparametric tests $\left(\chi^{2}\right.$ test with Yates correction, Fisher exact test when each cell had an expected frequency of $\geq 5$ ). Student's $t$-test and Mann-Whitney test were applied to the comparison of means in the case of continuous variables (Gaussian distribution or nonparametric variables, respectively). $P<0.05$ was considered to be significant.

\section{Ethical considerations}

The present study was approved by the Research Ethics Committee of Fundação Hospital Estadual do Acre (FUNDHACRE).

\section{Results}

\section{Comparison between $\mathbf{G 1}$ and $\mathbf{G 2}$}

No significant differences in socioeconomic or demographic variables were observed between the two groups (Table 1). With respect to the gynecologic-obstetric history, only the duration of breast-feeding of the last child showed a significant difference (G1: $4.4 \pm 4.5$ months vs G2: $8.8 \pm 5.9$ months; $P<0.004$ ). Both groups were comparable regarding number of offspring, abortions and sexual partners (Table 2). Regarding the risk factors for HBV infection, the shared use of toothbrushes between the HBV carriers and household contacts was identified in $72.7 \%(16 / 22)$ of G1 individuals and in $20.5 \%(9 / 44)$ of G2 individuals $(P<0.0001$; Table 3). The presence of at least one HBV carrier among members of the family of origin (parents, brothers and sisters) was observed in $75 \%(15 / 20)$ and $6.5 \%(2 / 31)$ of G1 and G2 patients, respectively $(P<0.001)$. Shared use of the toothbrush and the presence of more than one HBV carrier in the family of origin differed significantly between the two groups (Table 3 ).

Table 1 Subject characteristics

\begin{tabular}{|c|c|c|c|}
\hline Variable & $\mathrm{G} 1(n=22) n(\%)$ & $\mathrm{G} 2(n=44) n(\%)$ & $P$ \\
\hline Age, years (mean $\pm S D$ ) & $25.1 \pm 3.4$ & $24.6 \pm 3.8$ & $0.62^{\dagger}$ \\
\hline \multicolumn{4}{|l|}{ Marital status } \\
\hline Single & $6(27.3)$ & $16(36.4)$ & \multirow[t]{2}{*}{$0.45^{\ddagger}$} \\
\hline Other & $16(72.7$ & $28(63.6)$ & \\
\hline \multicolumn{4}{|l|}{ Present occupation } \\
\hline Housewife & $18(81.8)$ & $28(63.6)$ & \multirow[t]{2}{*}{$0.21^{\ddagger}$} \\
\hline Other & $4(18.2)$ & $16(36.4)$ & \\
\hline \multicolumn{4}{|l|}{ Education level } \\
\hline Illiterate or incomplete first grade school & $13(59.1)$ & $22(50.0)$ & \multirow[t]{2}{*}{$0.48^{\ddagger}$} \\
\hline$>1$ year spent in school & $9(40.9)$ & $22(50.0)$ & \\
\hline
\end{tabular}

G1, HBsAg-positive cases; G2, HbsAg-negative cases.

${ }^{\dagger}$ Student's $t$-test; ${ }^{\ddagger} \chi^{2}$ test with Yates' correction. 
Table 2 Gynecologic-obstetric history

\begin{tabular}{|c|c|c|c|}
\hline Variable & G1 (Mean \pm SD) & G2 (Mean \pm SD) & $P$ \\
\hline No. offspring ${ }^{\dagger}$ & $31.2(2.3 \pm 1.7)$ & $34.6(2.5 \pm 1.6)$ & $0.47^{\ddagger}$ \\
\hline No. abortions ${ }^{\dagger}$ & $31.2(0.4 \pm 0.9)$ & $34.6(0.4 \pm 0.8)$ & $0.37^{\ddagger}$ \\
\hline Age at 1 st sexual intercourse (years) & $16.2 \pm 2.6$ & $15.2 \pm 2.0$ & $0.09^{\S}$ \\
\hline Time with a fixed partner (years) & $5.6 \pm 3.7$ & $5.3 \pm 5.0$ & $0.86^{\S}$ \\
\hline Duration of breast-feeding" (months) & $4.4 \pm 4.5$ & $8.8 \pm 5.9$ & $0.004^{\S}$ \\
\hline
\end{tabular}

G1, HBsAg-positive cases; G2, HbsAg-negative cases.

${ }^{\dagger}$ Mean rank; ${ }^{\ddagger}$ non-parametric Mann-Whitney test; ${ }^{5}$ Student's t-test.

"Breast-feeding duration for the last child.

Table 3 Distribution of probable risk factors for HBV

\begin{tabular}{|c|c|c|c|}
\hline Risk factor & $\mathrm{G} 1(n=22) \%(n)$ & $\mathrm{G} 2(n=44) \%(n)$ & $P$ \\
\hline Percutaneous exposure & $0.0(0)$ & $2.3(1)$ & $1.0^{\dagger}$ \\
\hline Blood derivatives & $13.6(3)$ & $22.7(10)$ & $0.58^{\ddagger}$ \\
\hline Injections with a glass device & $31.8(7)$ & $43.2(19)$ & $0.37^{\S}$ \\
\hline Puncture of the finger & $50.0(11)$ & $52.3(23)$ & $0.86^{\S}$ \\
\hline Dental treatment & $9.1(2)$ & $2.3(1)$ & $0.26^{\dagger}$ \\
\hline Surgery & $0.0(0)$ & $0.0(0)$ & - \\
\hline Use of injectable or inhalatory drugs & $13.6(3)$ & $4.5(2)$ & $0.32^{\dagger}$ \\
\hline Tattooing & $59.1(13)$ & $56.8(25)$ & $0.86^{\S}$ \\
\hline Razor blade $^{1}$ & $86.4(19)$ & $81.8(36)$ & $0.91^{\ddagger}$ \\
\hline Toothbrush sharing ${ }^{1}$ & $72.7(16)$ & $20.4(9)$ & $<0.0001^{\text {s }}$ \\
\hline Nail clippers ${ }^{1}$ & $54.5(12)$ & $31.8(14)$ & $0.07^{\S}$ \\
\hline Skin Wounds (old/recent) ${ }^{2}$ & $0.0(0)$ & $2.3(1)$ & $1.0^{\dagger}$ \\
\hline \multicolumn{4}{|l|}{ Sexual exposure } \\
\hline Oral sex & $13.6(3)$ & $31.8(14)$ & $0.11^{\ddagger}$ \\
\hline Anal sex & $27.3(6)$ & $20.5(9)$ & $0.53^{\S}$ \\
\hline Use of a condom & $68.2(15)$ & $43.2(19)$ & $0.05^{\S}$ \\
\hline No. of partners during the last 6 months & & & $1.0^{\dagger}$ \\
\hline Up to one partner & $95.5(21)$ & $93.2(41)$ & \\
\hline More than one partner & $4.5(1)$ & $6.8(3)$ & \\
\hline History of sexually transmitted diseases & $9.1(2)$ & $6.8(3)$ & $1.0^{\dagger}$ \\
\hline Gonorrhea & $9.1(2)$ & $0.0(0)$ & $0.11^{\dagger}$ \\
\hline Syphilis & $4.5(1)$ & $2.3(1)$ & $1.0^{\dagger}$ \\
\hline Condyloma & $4.5(1)$ & $2.3(1)$ & $1.0^{\dagger}$ \\
\hline Herpes & $0.0(0)$ & $0.0(0)$ & - \\
\hline HIV & - & - & - \\
\hline \multicolumn{4}{|l|}{ Family contact (family of origin) } \\
\hline At least one family member & $75.0(15 / 20)$ & $6.5(2 / 31)$ & $<0.0001^{\ddagger}$ \\
\hline Genitor with hepatitis (HBsAg +) & $21.1(4 / 19)$ & $7.1(2 / 28)$ & $0.2^{\dagger}$ \\
\hline Siblings with hepatitis $(\mathrm{HBsAg}+)$ & $75.0(12 / 16)$ & $0(0 / 13)$ & $<0.0001^{\dagger}$ \\
\hline
\end{tabular}

G1, HBsAg-positive cases; G2, HbsAg-negative cases.

${ }^{1}$ Shared; ${ }^{2}$ impetico, escrofuloderms, escabiose, leishmaniose.

${ }^{\dagger}$ Fisher test; ${ }^{+}$Yates correlation; ${ }^{\S} \chi^{2} / \chi^{2}$ test with Yates' correction; "Bonferroni, significant if $P<0.002$.

\section{Sexual partners}

Evidence of HBV carrier stage of the present sexual partner was significant in the two groups, with $4 / 19(21.0 \%)$ and $1 / 40(2.5 \%)$ in G1 and G2, respectively $(P<0.04)$. In addition, $73.7 \%(14 / 19)$ of G1 partners and $45 \%(18 / 40)$ of G2 partners were positive for anti-HBc (IgG; $P<0.04)$.

\section{Offspring}

The frequency of HBsAg was $10.4 \%$ (5/48) in offspring of G1 and $1.9 \%(2 / 105)$ in offspring of $\mathrm{G} 2(P<0.03)$. Anti-HBc $(\operatorname{IgG})$ was detected in $37.5 \%$ (18/48) of G1 offspring and 6.7\% (7/105) of G2 offspring. When the children of G1 and G2 mothers were separated according to age, a significant difference in anti-HBc (IgG) 
Table 4 Presence of HBsAg/anti-HBc (lgG) in children from G1 and G2 mothers according to age group

\begin{tabular}{|c|c|c|c|c|c|c|}
\hline \multirow[b]{2}{*}{ Age group (years) } & \multicolumn{3}{|c|}{$\mathrm{HBsAg}$} & \multicolumn{3}{|c|}{ Anti-HBc (lgG) } \\
\hline & $\mathrm{G} 1 \%(n)(+)$ & $\mathrm{G} 2 \%(n)(+)$ & $P$ & $\mathrm{G} 1 \%(n)(+)$ & $\mathrm{G} 2 \%(n)(+)$ & $P$ \\
\hline$<1$ & $16.7(3 / 18)$ & $0(0 / 17)$ & $0.2^{+}$ & $66.7(12 / 18)$ & $0(0 / 17)$ & $<0.0002^{\S}$ \\
\hline $1-3$ & $7.7(1 / 13)$ & $0(0 / 34)$ & $0.2^{+}$ & $66.7(12 / 18)$ & $2.9(1 / 39)$ & $0.4^{\dagger}$ \\
\hline $4-6$ & $11.1(1 / 9)$ & $0(0 / 23)$ & $0.2^{+}$ & $33.3(3 / 9)$ & $4.3(1 / 23)$ & $0.05^{\dagger}$ \\
\hline $7-10$ & $0(0 / 5)$ & $4.2(1 / 24)$ & $1.0^{\dagger}$ & $20(1 / 5)$ & $12.5(3 / 24)$ & $0.5^{\dagger}$ \\
\hline $11-13$ & $0(0 / 2)$ & $0(0 / 2)$ & - & $50(1 / 2)$ & $0(0 / 2)$ & $1.0^{\dagger}$ \\
\hline $14-16$ & $0(0 / 1)$ & $0(0 / 3)$ & - & $0(0 / 1)$ & $0(0 / 3)$ & - \\
\hline$>16$ & $0(0 / 0)$ & $50(1 / 2)$ & - & $0(0 / 0)$ & $100(2 / 2)$ & - \\
\hline Total & $10.4(5 / 48)$ & $1.9(2 / 105)$ & $<0.04^{\dagger}$ & $37.5(18 / 48)$ & $6.77 / 105$ & $<0.000002^{\ddagger}$ \\
\hline
\end{tabular}

$\mathrm{G} 1$, index group; $\mathrm{G} 2$, control group.

${ }^{\dagger}$ Fisher test; ${ }^{\ddagger} \chi^{2}$ test; ${ }^{5} \chi^{2}$ test with Yates' correction.

Table 5 Presence of HBsAg and/or total anti-HBc

\begin{tabular}{|c|c|c|c|c|c|c|}
\hline \multirow[b]{2}{*}{ Family } & \multicolumn{3}{|c|}{$\mathrm{HBsAg}$} & \multicolumn{3}{|c|}{ Anti-HBc (lgG) } \\
\hline & $\mathrm{G} 1 \%(n)(+)$ & $\mathrm{G} 2 \%(n)(+)$ & $P$ & $\mathrm{G} 2 \%(n)(+)$ & G1\% (n) (+) & $P$ \\
\hline Parents" & $27.3(6 / 22)$ & $4.5(2 / 44)$ & $<0.03^{\S}$ & $86.4(19 / 22)$ & $54.5(24 / 44)$ & $<0.03^{\S}$ \\
\hline Mother & $21.1(4 / 19)$ & $7.1(2 / 28)$ & $0.2^{\dagger}$ & $100(19 / 19)$ & $71.4(20 / 28)$ & $<0.04^{\ddagger}$ \\
\hline Father & $33.3(3 / 9)$ & $0(0 / 10)$ & $0.09^{\dagger}$ & $100(9 / 9)$ & $60(6 / 10)$ & $0.09^{\dagger}$ \\
\hline Sexpartner & $21.1(4 / 19)$ & $2.5(1 / 40)$ & $<0.04^{\dagger}$ & 73.7 (14/19) & $45.0(18 / 40)$ & $<0.04^{\ddagger}$ \\
\hline Siblings & $75(12 / 16)$ & $0(0 / 13)$ & $<0.00006^{\dagger}$ & $100(19 / 19)$ & $81.3(13 / 16)$ & $0.08^{\dagger}$ \\
\hline Offsprings & $10.4(5 / 48)$ & $1.9(2 / 105)$ & $<0.04^{\dagger}$ & $37.5(18 / 48)$ & $6.7(7 / 105)$ & $<0.000002^{\ddagger}$ \\
\hline Lastchild & $18.2(4 / 22)$ & $0(0 / 44)$ & $<0.01^{\dagger}$ & $59.1(13 / 22)$ & $2.3(1 / 44)$ & $<0.0000005^{\S}$ \\
\hline Others & $22.2(4 / 18)$ & $9.7(3 / 31)$ & $0.3^{\dagger}$ & $72.2(13 / 18)$ & $51.6(16 / 31)$ & $0.1^{\S}$ \\
\hline
\end{tabular}

$\mathrm{G} 1$, index group; $\mathrm{G} 2$, control group.

${ }^{\dagger}$ Fisher test; ${ }^{\ddagger} \chi^{2}$ test; ${ }^{5} \chi^{2}$ test with Yates' correction.

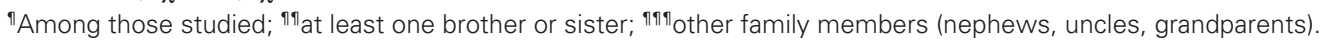

positivity was observed for children aged $<1$ year in G1 $(66.7 \%$, $12 / 18)$ compared to $\mathrm{G} 2(0 \%, 0 / 17 ; P<0.0002)$, while for children aged 4-6 years, this proportion was $33.3 \%(3 / 9)$ and $4.3 \%(1 / 23)$ in $\mathrm{G} 1$ and $\mathrm{G} 2$, respectively $(P=0.05)$. No significant differences in anti-HBc ( $\operatorname{IgG})$ positivity were observed for the other age groups, and there was no difference in the frequency of HBsAg between $\mathrm{G} 1$ and $\mathrm{G} 2$ children when stratified by age (Table 4). Of a total of $81.8 \%(54 / 66)$ of children who had completed vaccination for $\mathrm{HBV}, 83.3 \%(45 / 54)$ showed no evidence of HBV infection (HBsAg and anti-HBc [IgG] negative, with 77.8\% [35/45] of the children presenting post-vaccination seroconversion [anti-HBs]; $57.1 \%$ in G1 vs $81.6 \%$ in G2, $P>0.1$ ). Only $18 \%(4 / 22)$ of G1 children received hyperimmune hepatitis $\mathrm{B}$ immunoglobulin (HBIG) and a vaccine during the first day of life. Of the children aged $<6$ months who had not completed the vaccination scheme, $66.7 \%(2 / 3)$ were $\mathrm{HBsAg}$ positive and $100 \%$ (3/3) were anti-HBc (IgG) positive (Table 4).

\section{Others household contacts}

Overall positivity for HBsAg was $24.3 \%$ (42/173) in G1 and $3.2 \%$ $(10 / 315)$ in $\mathrm{G} 2(P<0.0000000002)$. Anti-HBc $(\mathrm{IgG})$ was present in $70.5 \%(124 / 176)$ of G1 family members and in $33.1 \%(105 / 318$; $P<0.000003)$ of $\mathrm{G} 2$ members $(P<0.0000001$; Table 4$)$. The HBsAg positivity in G1 was observed for all age groups and was higher for individuals aged 11-30 years and >50 years. However, in G2, HBsAg positivity was observed only in individuals $>21$ years $(P<0.0000001)$, with individuals $>26$ years having the highest positivity $(P<0.0000001)$. No significant difference in HBsAg or anti-HBc ( $\operatorname{IgG})$ positivity was observed between male and female subjects in the same group (G1, $P>0.23$ and $P>0.47$; G2, $P>0.49$ and $P>0.92$ ), but the difference was highly significant when the two groups were compared $(P<0.05)$. In summary the frequency of HBV carriers and of individuals exposed to the virus was higher among siblings, followed by parents, sexual partners and offspring (Table 5).

\section{Hepatitis B virus genotypes}

From the $72 \mathrm{HBsAg}$-positive individuals, HBV-DNA was positive in only 31 , while 17 samples had insufficient material and 24 had undetectable HBV-DNA by polymerase chain reaction (PCR). Although the analysis was restricted to 31 samples, there was a trend for concentration of the same genotypes in the same families. Remarkably, few cases with genotype F were found, contrasting with a higher frequency of genotype A and D. Surprisingly, genotype $\mathrm{G}$ was found in some cases (Table 6).

\section{Discussion}

Transmission of HBV between household contacts seems to be important in areas of high endemicity. In the present study, the 
Table 6 Genotype analysis with Innolipa test

\begin{tabular}{llll}
\hline Family & HBsAg positive & HBV-DNA by PCR & Genotype \\
\hline 01 & 03 & NR & NR \\
02 & 03 & 02 & A, D + G \\
03 & 05 & NR & NR \\
04 & 01 & NR & NR \\
05 & 01 & 01 & D + G \\
06 & 10 & 04 & All A \\
07 & 02 & 02 & F, A \\
08 & 02 & 01 & A \\
09 & 04 & 01 & A \\
10 & 04 & NR & NR \\
11 & 04 & NR & NR \\
12 & 02 & 01 & A \\
13 & 04 & 01 & A \\
14 & 01 & 01 & D \\
15 & 02 & 01 & A \\
16 & 01 & 02 & A, A +D \\
17 & 03 & 02 & A, D \\
18 & 01 & NR & NR \\
19 & 01 & 02 & A, D \\
20 & 13 & 08 & All D + G \\
21 & 06 & 01 & A + F \\
22 & 05 & 01 & D \\
\hline
\end{tabular}

NR, non-reacted; PCR, polymerase chain reaction.

Samples excluded: 17 insufficient material; 24 HBV-DNA (PCR) negative; 31 HBV-DNA by PCR positive.

overall prevalence of HBsAg was $10.1 \%$, a value similar to those reported in other studies carried out in the Amazon region, which showed a high prevalence of HBV infection. ${ }^{8,9}$ The frequency of infection among household contacts was 10-fold higher in family members and sexual partners of index cases (G1) compared to the control group (G2), Furthermore the difference was approximately twofold lower in the case of exposed individuals (anti-HBc IgG).

The prevalence of HBV markers increased progressively with age. ${ }^{10-12}$ This finding points to an early exposure during life in the Brazilian Amazonian region. It is in agreement with our observation in hospitalized patients, of young patients with cirrhosis due to HBV. Considering only the family members who lived in the same house, in the present study a higher frequency of anti-HBc (IgG) was found among household contacts, although no statistical significance between genders was observed in the same group. This is in contrast to other studies that found a trend towards higher positivity among men. ${ }^{13}$ This difference may be explained by the higher number of female siblings and offspring.

In the present study, intrafamilial dissemination was clearly observed. This aspect has yielded conflicting results in other studies. ${ }^{14-16}$ Lok and other authors did not confirm these results in China. Again the selection methods could explain opposite results.

The results of the present study are also in agreement with those reported in the literature in terms of the elevated positivity for HBV markers in families consisting of a larger number of members and more than one HBV carrier. ${ }^{17}$

Various factors are related to the risk of intrafamilial transmission of HBV, including exposure to the body fluids of an infected person with skin wounds, and the shared use of personal hygiene items such as toothbrushes, towels, nail scissors and shavers. ${ }^{18,19}$ In the present study, the shared use of toothbrush was found to be strongly associated with HBV transmission through household contacts. Sharing a toothbrush was considered when the individual reported this habit at least once in the last 6 months with any household member. It is a common habit among family members of poorer populations of the region, indicating the need for the establishment of preventive and educational measures in order to prevent this practice. Unfortunately, our databank did not permit cross-referencing of this variable with sexual partnership. If an individual who shared toothbrushes was, at the same time, a sexual partner, we could not determine which one was involved in the viral transmission. In any case, only few adults reported sharing of toothbrushes, which makes sexual partnership less probable as a confounding variable.

Interestingly, in the present study the frequency of HBsAg positivity of the last child was higher in infants who were not breastfed. However, due to the small sample size, we cannot exclude breast-feeding as a risk factor for HBV transmission in this group, although, as a rule, breast-feeding should not be discontinued even when the mothers are HBsAg positive because the risk of transmission is very low. ${ }^{20}$ This is an important question in developing countries.

Genotype analysis was performed in only 31 samples, probably because of storage and transportation troubles and/or very low viral load. Despite the small number of samples our results are provoking and deserve further study. Few cases of genotype F were seen, in contrast with the high prevalence of this genotype in this area. ${ }^{21}$ This could be because the present study was conducted in a big Amazonian city where native (Amerindians) compose the minority of the population. Because genotype $\mathrm{F}$ is considered prevalent in native populations of the Americas (Alaska and the Amazonian), then its presence in cosmopolitan cities could be modest. In contrast, we had $24 \mathrm{HBV}$-DNA (PCR)-negative samples. Taking into consideration anecdotal experience regarding genotype $\mathrm{F}$ (data not published) and a trend to a low viral load, some of these samples could indeed be F genotypes. New sample collection with more careful storage is needed to better clarify this point.

Another surprising result regarding genotype analysis was the presence of genotype $\mathrm{G}$, which has never been described in this area before. In addition, double genotype was recognized by Innolipa test in the same patient. These results should be confirmed with full sequencing of the viral genome, to confirm genotype $\mathrm{G}$ in the Amazonian, as well as to observe the possibility of genome recombination. $^{22}$

Another aspect that deserves further clarification is the role of viral load in the efficiency of intrafamilial transmission of HBV. Unfortunately, there are no HBV-DNA commercial kits in Brazil so these data were not available in the present study.

In conclusion, the present study provided strong evidence for the intrafamilial transmission of $\mathrm{HBV}$, with the frequency of $\mathrm{HBV}$ markers being higher among families with more than one HBsAg carrier and among those who habitually share toothbrushes. Further studies are necessary to better establish the route of dissemination of HBV in the Brazilian Amazon region.

\section{Acknowledgment}

This paper received financial support from INSERM (France); CNPq-International Capes/COFECUB project 404/02. 


\section{References}

1 Fonseca FCF. Epidemiologia das hepatites B e Delta na região Amazônica. Skopia 1988; 23: 28-32.

2 Bensabath G, Hadler SC, Soares MPC, Fields H, Maynard JE. Epidemiologic and serologic studies of acute viral hepatitis in Brazil's Amazon Basin. Bull. Pan Am. Health Organ. 1987; 21: 16-27.

3 Braga WSM, Brasil LM, Panula M, Carvalho JAB. Epidemiological aspects of hepatitis B virus (HBV) infection in children, Beruri, Amazonas. Acta Hepatol. 1991; 1: 23-4.

4 Brasil LM, Braga WSM, Souza RAB, Castilho MC, Fonseca JCF. The prevalence of hepatitis B virus (HBV) markers within household in the state of Amazonas, Brazil. Hepatology 1994; 19: 451.

5 Bernier RH, Sampliner R, Gerety R, Tabor E, Hamilton F, Nathanson N. Hepatitis B infection in households of chronic carriers of hepatitis B surface antigen: factors associated with prevalence of infection. Am. J. Epidemiol. 1982; 116: 199-211.

6 Porres JC, Carreño V, Bartolomé J, Gutiez J, Castillo I. A dynamic study of the intrafamilial spread of hepatitis B virus infection: relation with the viral replication. J. Med. Virol. 1989; 28: 237-42.

7 Szmuness W, Harley EJ, Prince AM. Intrafamilial spread of asymptomatic hepatitis B. Am. J. Med. Sci. 1975; 270: 293-304.

8 Brasil LM, Carvalho JA, Castilho MC, Fonseca JCF. Estúdio en portador asintomaticos del vírus de la hepatitis B (HBV): Aspectos regionales y demográficos, Amazonas, Brasil. Gen. Venezuela 1992; 46: $267-9$.

9 Souto FJ. Hepatitis B and the human migratory movements in the State of Mato Grosso, Brazil. Rev. Soc. Bras. Med. Trop. 2004; 37(Suppl. 2): 63-8.

10 Toukan AU, Sharalha ZK, Abu-el-Rub OA et al. The epidemiology of hepatitis B virus among family members in the Middle East. Am. J. Epidemiol. 1990; 132: 220-32.

11 Moretti A, D'Albasio G, Scartabelli S et al. Epidemiology of viral hepatitis. Clinical considerations on a hospital caseload. Recent Prog. Med. 1977; 63: 471-96.

12 Kim YS, Ahn YO. Factors associated with intrafamilial transmission of hepatitis B virus infection in Korea. J. Korean Med. Sci. 1993; 8: 395-404.

13 Brasil LM, Braga WSM, Castejon MJ, Fonseca JCF. Prevalence of hepatitis B virus (HBV) infection in children, Codajás, Amazon basin, Brazil: a pre-study vaccination. Acta Hepatol. 1991; 1: 26.

14 Lok ASF, La CL, Wu PC. Hepatitis B virus infection in Chinese families in Hong Kong. Am. J. Epidemiol. 1987; 126: 492-9.

15 Szmuness W, Prince AM, Hirsch RL, Brotman B. Familial clustering of hepatitis B infection. N. Engl. J. Med. 1973; 289: 1162-6.

16 Hsu SC, Chang MH, Ni YH, Hsu HY, Lee CY. Horizontal transmission of hepatitis B vírus in children. J. Pediatr. Gastroenterol. Nutr. 1993; 16: 66-9.

17 Goh KT, Ding JL, Monteiro EH, Oon CJ. Hepatitis B infection in households of acute cases. J. Epidemiol. Community Health 1993; 39: 123-8.

18 Tan CC, Guan R, Yap I, Tay HH, Kang JY. Horizontal or vertical transmission of hepatitis B virus? A serological survey in family members of hepatitis B carriers in Singapore. Trans. R. Soc. Trop. Med. Hyg. 1991; 85: 656-9.

19 Erol S, Ozkurt Z, Ertek M, Tasyaran MA. Intrafamilial transmission of hepatitis B virus in the eastern Anatolian region of Turkey. Eur. $J$. Gastroenterol. Hepatol. 2003; 15: 345-9.

20 Alter M. Epidemiology of hepatitis B in Europe and worldwide. In: Marcellin ED, ed. EASL International Consensus Conference in Hepatitis B-Syllabus. Geneva: EASL, 2002;18: 73-81.

21 Araus-Ruiz P, Nonder H, Visona K, Magnius LO. Genotype F prevails in HBV infected patients of hispanic origin in Central América and may carry the precore stop mutant. J. Med. Virol. 1997; 51: 305-12.

22 Kidd-Ljungre K, Miyakawa Y, Kidd AH. Genetic variability in hepatitis B genome. J. Gen. Virol. 2002; 83: 1267-80. 